\title{
Dietary Knowledge, Attitude and Practice (KAP) Among the Family Members of Patients with Type 2 Diabetes Mellitus (T2DM) and Its Influence on the KAP of T2DM Patients
}

This article was published in the following Dove Press journal:

Diabetes, Metabolic Syndrome and Obesity: Targets and Therapy

\section{Xiling $\mathrm{Hu} \mathbb{D}^{1}{ }^{1} *$ \\ Yao Zhang ${ }^{2, *}$ \\ Shuo $\operatorname{Lin}^{2}$ \\ Xiaodi Guo \\ Dan Yang ${ }^{3}$ \\ Mengyin $\mathrm{Cai}^{2} * *$ \\ Lingling $\mathrm{Gao}^{3, *}$}

'Department of Medicine, The Third Affiliated Hospital of Sun Yat-Sen University, Guangzhou, People's Republic of China; ${ }^{2}$ Department of Endocrinology and Metabolism, The Third Affiliated Guangzhou, People's Republic of China; ${ }^{3}$ School of Nursing, Sun Yat-Sen University, Guangzhou, People's Republic of China

*These authors contributed equally to this work Hospital of Sun Yat-Sen University,

\begin{abstract}
Purpose: To investigate the dietary knowledge, attitude and practice (KAP) among the family members (FMs) of Chinese type 2 diabetes mellitus (T2DM) patients and its influence on the KAP of T2DM patients.

Patients and Methods: Two hundred thirty-six pairs of hospitalized T2DM patients and their FMs (472 in total) in our hospital were enrolled. A pair of self-designed questionnaires on dietary KAP (Cronbach's $\alpha \geq 0.763$, I-CVI $\geq 0.857$, S-CVI $=0.964,0.958$ ) were used to collect data and assess the KAP towards diabetes diets.

Results: The mean score for dietary KAP of T2DM patients was $2.33 \pm 0.60,3.03 \pm 0.44$ and $2.77 \pm 0.38$, whereas that of their FMs was $2.37 \pm 0.55,3.08 \pm 0.48$ and $2.82 \pm 0.61$, respectively. Pearson's correlation analysis showed that the glycosylated hemoglobin (HbA1c) of T2DM patients was negatively correlated to their dietary practice $(r=-0.218$, $P<0.01)$. There was a positive correlation between T2DM patients and their FMs for dietary KAP $(r=0.306, P<0.05)$. The dietary practice of T2DM patients was positively correlated with the dietary KAP of their FMs $(r=0.305,0.252$ and 0.136 , respectively, $P<0.01)$. Logistic regression analysis revealed that the score for dietary knowledge and attitude, occupation, residence, family history, complications of the T2DM patient, and the sex and dietary knowledge score of the FM were significantly associated with dietary practice for T2DM patients.
\end{abstract}

Conclusion: The dietary attitude of FMs was moderate but dietary knowledge and practice were poor. Dietary KAP was positively correlated with T2DM patients and their FMs.

Keywords: type 2 diabetes mellitus, self-management, family characteristics

\section{Introduction}

Department of Endocrinology and

Metabolism, The Third Affiliated Hospital of Sun Yat-Sen University, No. 600 Tianhe Road, Guangzhou, Guangdong 510630,

People's Republic of China

Tel +86 |3922|3|45|

Email my.sabrina.c@163.com

Lingling Gao

School of Nursing, Sun Yat-Sen University,

No. 74, Zhongshan Er Road, Guangzhou, Guangdong 510085, People's Republic of

China

Tel +8613539965693

Email gaoll@mail.sysu.edu.cn
Diabetes mellitus (DM) is characterized by hyperglycemia. DM is related to abnormalities in the metabolism of carbohydrates, fats and proteins, which results in chronic complications, including macrovascular, microvascular, and neuropathic disorders. The International Diabetes Federation (IDF) has estimated that one in 11 adults is living with DM currently. This estimate translates to $\sim 465$ million people worldwide, and this number is expected to increase to $\sim 700$ million people by 2045. ${ }^{1}$ Hence, the prevention and management of DM has become a major health challenge worldwide. One significant change in the latest American Diabetes Association (ADA) guideline Standards of Medical Care in Diabetes - 2020 is 
that "lifestyle management" has been changed to "facilitating behavior change and well-being to improve health outcomes". This change more appropriately emphasizes how effective behavior management and psychological well-being are crucial to achieving treatment goals for people suffering from DM. ${ }^{2}$ Practicing effective behavior management of the diet in DM patients can result in improved medical outcomes (eg, reduction in the level of HbAlc and blood pressure, decrease in cholesterol, reduced weight), and cost-effective care for patients and healthcare systems. ${ }^{2,3,15}$

The dietary practice of DM patients is influenced by their dietary knowledge and attitudes. Thus, some studies have focused on the knowledge, attitude and practice (KAP) of people with DM towards nutrition and diet, and mixed results have been obtained. ${ }^{4-8}$ However, most of a patient's lifetime is spent at home with family members (FMs), and patients are readily affected by these FMs. Hence, family factors are increasingly recognized as having an important impact on the care of people with DM. ${ }^{9,17-21}$ Moreover, one study indicated that FMs provided diabetes-specific support most frequently with regard to medication adherence and exercise, which might be because it is easier to provide assistance in this regard than to provide help in diet management. ${ }^{10}$ Due to the culture in China and the previous One Child government policy, it is quite common for 2-3 generations to live or eat together in China, resulting in more interactions in family dynamics. According to Interdependence Theory and Family Systems Theory, interactions in a family affect both patients and FMs and changes in one FM influence all others FMs. ${ }^{9}$ Some studies have illustrated the benefits of including the family dimension in the care of DM patients in the overall diabetes-related outcome and quality of life. ${ }^{9-12}$ However, no study has been performed on KAP towards diabetes diet (DD) among the FMs of Chinese people with T2DM and its influence on the KAP of such patients. Such a study would provide better insights into how FM interventions can reduce the burden of T2DM, and was the rationale for the present study.

\section{Patients and Methods}

\section{Ethical Approval of the Study Protocol}

The study protocol was approved by the ethics committee of the Third Affiliated Hospital of Sun Yat-sen University (Guangzhou, China). All participants provided written informed consent before study participation.

\section{Inclusion and Exclusion Criteria for}

\section{Patients FMs}

The inclusion criteria for T2DM patients group were: (i) diagnosed with T2DM according to the definition put forward by the World Health Organization in 1999; (ii) age $\geq 18$ years; (iii) DM diagnosis made $\geq 3$ months previously; (iv) having basic literacy (able to read and understand questions). The exclusion criteria for them were: (i) manage his/her diet totally by himself/herself; (ii) pregnancy; (iii) not able to complete the survey due to psychological/physical disorders (eg, acute complications of DM or serious illnesses of the heart, brain, lungs, or kidneys).

The inclusion criteria for FMs of T2DM patients were: (i) age $\geq 18$ years; (ii) designated by the T2DM patient; (iii) having a major influence on the T2DM patient's diet (eg, the patient's spouse, parents, adult children, siblings, or other relatives). The exclusion criteria for them were (i) having DM of any type; (ii) not able to complete the survey due to psychological disorders or serious illnesses of the heart, brain, lungs, or kidneys.

\section{Study Design}

A descriptive cross-sectional study was conducted between September 2018 and January 2019 in the Third Affiliated Hospital of Sun Yat-sen University. We enrolled 250 hospitalized T2DM patients with one of their FMs (ie, $250 \mathrm{~T} 2 \mathrm{DM}$ patients and $250 \mathrm{FMs}, 500$ people in total).

\section{Questionnaire and Data Collection Questionnaire Design}

There was one questionnaire for the T2DM patient and one questionnaire for the FM. The first part of the patient questionnaire was on demographic characteristics (sex, age, nationality, education level, occupation, marital status, source of diabetes knowledge) and disease-related information (current $\mathrm{HbAlc}$, treatment regimen, family history, dietary dominance). The first part of the FM questionnaire was on demographic characteristics (sex, age, nationality, relationship with patient) and care givingassociated information (experiences in managing DM, time, and difficulty in taking care of the patient). The second part of the patient questionnaire and FM questionnaire contained questions on KAP regarding the diabetes diet (DD), based on reviewing literature in China and overseas.

The first version of the second part of the questionnaire (ie, KAP) comprised 66 items with a four-point ordinal 
scale in each item. The rating scale was from 1 to 4 . After several discussions and modifications, the first version of this part of the questionnaire was sent to a panel of seven experts (two endocrinologists, one nutritionist, three clinical nurses, and one college teacher) by email. This was done to obtain amendments to aid the accuracy and relevance of each item using a four-point rating scale from 1 ("irrelevant") to 4 ("highly relevant"). Twenty items with item-level Content Validity Index (I-CVI) $<0.78$ were deleted and 11 items were refined moderately. The initial edition of the 46-item questionnaire (for the T2DM patient and FM) in two parts focusing on knowledge (items 1-16), attitude (items 17-27), practice (items 18-46) was formed.

\section{Pre-Study: Analyses of Reliability and Validity}

A pilot study on 21 pairs of T2DM cases and their FMs who were not included in the study was done. The validity and reliability of the questionnaire was analyzed using SPSS 20.0 (IBM, Armonk, NY, USA). In the questionnaire for T2DM patients, Cronbach's $\alpha$ for the second section (ie, KAP) was $0.921,0.882,0.763$, for knowledge, attitude, and practice, respectively. Also, I-CVI was $\geq 0.857$ and scale-level CVI (S-CVI) was 0.964. In the questionnaire for FMs, Cronbach's $\alpha$ for the second section (ie, KAP) was 0.939, 0.887, and 0.950, respectively, for knowledge, attitude, and practice. I-CVI was $\geq 0.857$ and S-CVI was 0.958 .

\section{Data Collection}

Questionnaires were administered by two researchers and two qualified professional nurses of endocrinology and metabolism trained as research assistants. Before distributing the questionnaire, researchers elucidated the aim of the study. Some attention was paid to patients and their families. For those who had problems in completing the questionnaires because of age, lack of literacy or visual impairment, researchers dictated questions to them and recorded their answers without providing hints. Repetitive checks were executed by trained researchers after the questionnaires were completed. Doublechecking and validation were undertaken when the answers from the questionnaires were inputted into the database.

\section{Factor Analysis of Questionnaires}

A total of 250 pairs of questionnaires were distributed. We collected 236 pairs; 14 pairs of the questionnaires could not be completed because patients were transferred to other departments or discharged. All data from 236 pairs of the questionnaires collected were preprocessed using factor analysis. The Kaiser-Meyer-Olkin (KMO) value for KAP in the patient questionnaire was 0.940, 0.888, and 0.846, and the Bartlett test of sphericity was 2863.494, 1039.710, and 965.015 ( $\mathrm{P}<0.01$ for all), respectively. The KMO value for KAP in the FM questionnaire was 0.928, 0.906, and 0.947, and the Bartlett test of sphericity was 2685.562, 1560.029, and 2731.478, respectively $(\mathrm{P}<0.01)$. Principal component analysis was used to extract factor variables in the KAP section of the questionnaires. The cumulative contribution ratio of $\mathrm{KAP}$ in the patient questionnaire was $67.12 \%, 57.83 \%$, and $48.69 \%$, and that in the FM questionnaire was $70.21 \%, 65.52 \%$, and $60.95 \%$, respectively. After deleting item 40 with two factor loadings of $>0.4$, there were 45 items in the final KAP section of the patient questionnaire and FM questionnaire.

\section{Data Analyses}

Data were analyzed using SPSS 20 (IBM, Armonk, NY, USA). $\mathrm{P}<0.05$ (two-sided) was considered significant. Data are the mean $\pm \mathrm{SD}$ (for continuous variables) or as number and percentage (for categorical variables). Data were compared using Pearson's correlation analysis. Logistic regression was used to analyze factors associated with the patient's dietary practices with FM's KAP as well as demographic and disease-related variables.

\section{Results}

\section{Sociodemographic and Disease-Related Characteristics of T2DM Patients}

A total of $133(53.6 \%)$ T2DM patients were males. Also, $39.4 \%$ of T2DM patients had a college education or higher, whereas $20.3 \%$ had a primary and lower education level. We found that $54.2 \%$ of T2DM patients were employed and $86.9 \%$ were married. Also, $48.7 \%$ of patients never received DD-associated education. The three most prevalent sources of DD knowledge were clinicians and nurses (69.9\%), books, newspapers and magazines $(32.2 \%)$, and relatives and friends (31.4\%). We discovered that $66.1 \%$ of T2DM patients had a dietary dominance in the family.

We discovered that $59.7 \%$ of patients did not have a family history of DM. The duration of DM was 0.25-30 years, but for $41.5 \%$ of patients, the duration was $<5$ years. The mean number of diabetic complications 
was $1.00 \pm 1.07$. The three most prevalent complications were peripheral vascular disease, retinopathy, and peripheral neuropathy. The mean HbAlc level of patients was $8.85 \pm 2.43 \%$ and, in $73.3 \%$ of cases, the HbAlc level was $>7 \%$. The mean body mass index of patients was $23.94 \pm$ $3.74 \mathrm{~kg} / \mathrm{m}^{2}$, and $48.8 \%$ of them were overweight or obese.

\section{Sociodemographic Characteristics of FMs}

We found that $143(60.6 \%)$ FMs were the spouse and $157(66.5 \%)$ FMs were female. The mean age of FMs was $47.20 \pm 13.82$ years, and $24.2 \%$ of FMs had graduated from junior college/university. Also, $63.1 \%$ were employed. In addition, $62.7 \%$ of $\mathrm{FMs}$ had never received DD-associated education. The three most prevalent sources of DD knowledge were clinicians and nurses $(50.4 \%)$, relatives and friends $(39.8 \%)$, and television and radio (35.2\%). Also, the DD knowledge of $20.3 \%$ of FMs was from the patients they cared for, and $2.5 \%$ of FMs had never received any DD-associated information.

\section{Care-Giving-Associated Information of FMs}

We discovered that $82.2 \%$ of FMs had no experience of taking care of a relative with T2DM. Also, the daily duration of care-giving was $<2 \mathrm{~h}$ for $34.3 \%$ of FMs. In addition, $22.9 \%$ of FMs had been taking care of a relative with T2DM for $\geq 10$ years. Also, $43.2 \%$ of FMs had at least 1-2 types of difficulties in giving care to T2DM relatives, whereas $34.3 \%$ claimed no difficulty in routine care of a relative with T2DM.

\section{Association Between the HbAlc Level and Dietary Practice}

Pearson's correlation analysis showed that the $\mathrm{HbAlc}$ level of T2DM patients was negatively correlated with their dietary practice $(\mathrm{r}=-0.218, \mathrm{P}<0.01)$. Also, the $\mathrm{HbA1c}$ level was negatively associated with each of the four dietary practices shown in Table $1(\mathrm{r}=-0.087$ to $-0.344, \mathrm{P}<0.05$ ), among which the association between the $\mathrm{HbAlc}$ level and bad diet preferences was the strongest $(r=-0.344, P<0.01)$.

\section{KAP Regarding DD Among T2DM Patients}

KAP scores regarding DDs overall and in each dimension among participants with T2DM are shown in Table 2. The item mean score in the dimension DD knowledge in T2DM participants was $2.33 \pm 0.60$, indicating that their
Table I Association Between the HbAlc Level and Dietary Practice of T2DM Patients

\begin{tabular}{|l|l|}
\hline & $\begin{array}{l}\mathbf{H b A}_{\mathbf{I c}} \\
\mathbf{( \% )}\end{array}$ \\
\hline Dietary practice & $-0.218^{* *}$ \\
Cooking habits and self-monitoring & $-0.152^{*}$ \\
Bad diet preferences & $-0.344^{* *}$ \\
Reducing and increasing rate of blood glucose and & $-0.119^{* *}$ \\
hypoglycemia prevention & $-0.087^{*}$ \\
\hline Management of vegetables and meat &
\end{tabular}

Notes: $* * P<0.01, * P<0.05$.

Table 2 KAP Score with Regard Diabetes Diet (DD) Among T2DM Patients in Total and Each Dimensions $(n=236)$

\begin{tabular}{|c|c|c|c|}
\hline & & $\begin{array}{l}\text { Number } \\
\text { of Items }\end{array}$ & $\begin{array}{l}\text { Item Mean } \\
\text { Score }(x \pm \\
\text { s) }\end{array}$ \\
\hline Knowledge & $\begin{array}{l}\text { DD knowledge } \\
\text { Ratio and sources of } \\
\text { three main } \\
\text { macronutrients } \\
\text { Nutrient composition } \\
\text { and calculation } \\
\text { Dietary general } \\
\text { knowledge }\end{array}$ & $\begin{array}{l}16 \\
3\end{array}$ & $\begin{array}{l}2.33 \pm 0.60 \\
2.16 \pm 0.73 \\
2.17 \pm 0.65 \\
2.81 \pm 0.70\end{array}$ \\
\hline Attitude & $\begin{array}{l}\text { DD attitude } \\
\text { Knowledge of } \\
\text { importance of DDs } \\
\text { Belief in diet } \\
\text { management }\end{array}$ & $\begin{array}{l}11 \\
2 \\
9\end{array}$ & $\begin{array}{l}3.03 \pm 0.44 \\
3.46 \pm 0.57 \\
2.94 \pm 0.48\end{array}$ \\
\hline Practice & $\begin{array}{l}\text { DD practice } \\
\text { Cooking habits and } \\
\text { self-monitoring } \\
\text { Bad preference } \\
\text { Reducing the increasing } \\
\text { rate of blood glucose } \\
\text { Management of } \\
\text { vegetables and meat }\end{array}$ & $\begin{array}{l}18 \\
7 \\
4 \\
4 \\
3\end{array}$ & $\begin{array}{l}2.77 \pm 0.38 \\
2.92 \pm 0.47 \\
2.97 \pm 0.4 I \\
2.42 \pm 0.57 \\
2.65 \pm 0.58\end{array}$ \\
\hline
\end{tabular}

dietary knowledge was between "not quite clear" and "clear". In the dimension of dietary general knowledge, $36.9 \%$ of responses to the question item "How to react correctly to hypoglycemia?" was "totally unclear" and "not quite clear". In the dimension of nutrient composition and calculation, the score for the item "How to calculate the total calories you need every day?" was the lowest. In the dimension of the ratio and sources of the three main macronutrients, knowledge of protein was the lowest. 
The mean score of the item DD attitude in T2DM patients was highest $(3.03 \pm 0.44)$, indicating that the overall attitude towards DD was moderate. However, $8.9 \%$ of patients indicated "very unwilling" to "quite unwilling" to accept health education related to DD. In the dimension of belief in diet management, the item mean score was $2.94 \pm 0.48$, which was between "not quite confident" and "quite confident". The score for the question "Do you have confidence in persevering diabetes diet during holidays, birthday, and social banquet?" was the lowest among attitude items.

The item mean score of DD practice in T2DM patients was $2.77 \pm 0.38$, indicating that the overall DD practice was poor. Among four dimensions, the score for the "bad preference" dimension was the highest $(2.97 \pm 0.41)$, whereas the score for "reducing an increasing rate of blood glucose" was the lowest $(2.97 \pm 0.41)$. Undertaking prevention of hypoglycemia was the worst among overall dietary practices, and $64.8 \%$ of patients never or occasionally carried some sweets or biscuits with them in case of hypoglycemia.

Table 3 KAP Score Regarding Diabetes Diets (DD) Among Family Members in Total and Each Dimensions $(n=236)$

\begin{tabular}{|l|l|l|l|}
\hline \multicolumn{2}{|l|}{} & $\begin{array}{l}\text { Number } \\
\text { of Items }\end{array}$ & $\begin{array}{l}\text { Item } \\
\text { Mean } \\
\text { Score } \\
(x \pm s)\end{array}$ \\
\hline Knowledge & $\begin{array}{l}\text { DD knowledge } \\
\text { Ratio and sources of three } \\
\text { main macronutrients } \\
\text { Nutrient composition and } \\
\text { calculation }\end{array}$ & 3 & $\begin{array}{l}2.37 \pm 0.55 \\
2.19 \pm 0.67\end{array}$ \\
\hline $\begin{array}{l}\text { Dietary general } \\
\text { knowledge }\end{array}$ & 4 & $2.24 \pm 0.59$ \\
\hline Attitude & $\begin{array}{l}\text { DD knowledge } \\
\text { Knowledge of importance } \\
\text { of DDs } \\
\text { Confidence in diet } \\
\text { management }\end{array}$ & 2 & $2.80 \pm 0.68$ \\
\hline Practice & $\begin{array}{l}\text { DD practice } \\
\text { Cooking habits and } \\
\text { supervision } \\
\text { Bad preference } \\
\text { Reducing the increasing } \\
\text { rate of blood glucose } \\
\text { Management of vegetables } \\
\text { and meat }\end{array}$ & 3 & $\begin{array}{l}11 \\
3.08 \pm 0.48 \\
3.46 \pm 0.59\end{array}$ \\
\hline
\end{tabular}

\section{KAP Regarding DD Among FMs}

The KAP scores regarding DD overall and in each dimension among FMs are shown in Table 3. The item mean score of DD attitude among FMs was the highest $(3.08 \pm$ 0.48 ) and DD knowledge among them was the lowest $(2.82 \pm 0.61)$, which was similar to that seen in T2DM patients. In the dimension of dietary general knowledge, $42.4 \%$ of FM's response to the question "How to correctly react to hypoglycemia?" was "totally unclear" and "not quite clear", which was slightly more than that observed in T2DM patients. In the dimension of nutrient composition and calculation, the score of the question "Do you know the calculation method of ideal weight for people with type 2 diabetes?" was the lowest. In the dimension of the ratio and sources of three main macronutrients, knowledge of fat was the lowest.

We discovered that $9.3 \%$ of FMs indicated they were "very unwilling" and "quite unwilling" to accept health education related to $\mathrm{DD}$, which was slightly higher than that in T2DM patients. In the dimension of belief in diet management, the score for the question "Do you have confidence in supervising and helping patients to persevere with diabetes diet when patients feel it not suitable?" was the lowest.

Likewise, among four dimensions of DD practice, the score of the bad preference dimension was the highest $(2.93 \pm 0.69)$, whereas the score for reducing an increasing rate of blood glucose was the lowest $(2.65 \pm 0.73)$. The score for the questions "Do you supervise and help patients making food by boiling, steaming and salad avoiding wok-fried and smoked food?", "Do you remind and help patients to reduce the number of snacks (eg, French fries, melon seeds, jellies, biscuits) except for dealing with hypoglycemia", "Do you supervise and help patients add grains to staple food (eg, buckwheat, beans, nibbles)?", "Do you remind and help patients to control daily fruit intake within $200 \mathrm{~g}$ (about one medium-sized apple) when he/she has achieved an ideal glycemic status?" in the respective dimensions was the lowest. The score for helping patients to add some coarse grains into staple food was the worst: $47.0 \%$ of FMs responded with "never" or "occasionally".

\section{Association Between KAP Among T2DM Patients and FMs}

According to Pearson's correlation analysis, multiple comparisons of KAP scores among T2DM patients revealed positive correlations $(r=0.297-0.407, \mathrm{P}<0.01)$ and those 
Table 4 Association Between KAP Among T2DM Patients and Their Family Members

\begin{tabular}{|l|l|l|l|l|l|}
\hline & I & $\mathbf{2}$ & $\mathbf{3}$ & $\mathbf{4}$ \\
\hline I. Dietary knowledge of FMs & $\mathrm{I}$ & & & \\
2. Dietary attitude of FMs & $0.244^{* *}$ & $\mathrm{I}$ & & \\
3. Dietary practice of FMs & $0.446^{* *}$ & $0.454^{* *}$ & $\mathrm{I}$ & \\
4. Dietary knowledge of T2DM patients & $0.43 \mathrm{I}^{* *}$ & $0.18 \mathrm{I}^{* *}$ & $0.164^{*}$ & $\mathrm{I}$ \\
5. Dietary attitude of T2DM patients & $0.134^{*}$ & $0.506^{* *}$ & $0.266^{* *}$ & $0.297^{* *}$ & \\
6. Dietary practice of T2DM patients & $0.305^{* *}$ & $0.252^{* *}$ & $0.136^{*}$ & $0.407^{* *}$ & 1 \\
\hline
\end{tabular}

Notes: $* * \mathrm{P}<0.01, * \mathrm{P}<0$.

among their FMs were also positive $(r=0.244-0.454$, $\mathrm{P}<0.01$ ) (Table 4). Multiple comparisons among KAP scores of T2DM patients and those of their FMs showed positive pairwise correlations $(\mathrm{r}=0.134-0.506, \mathrm{P}<0.05)$. Moderate positive correlations were found between dietary knowledge of T2DM patients and that of their FMs $(r=0.431, \mathrm{P}<0.01)$ and also between dietary attitude of T2DM patients and that of their FMs $(\mathrm{r}=0.506, \mathrm{P}<0.01)$. The positive correlation between the dietary practices of T2DM patients and knowledge, attitude, and practice of their FMs was 0.305, 0.252, and 0.136 , respectively $(\mathrm{P}<0.05)$.

\section{Univariate Analysis and Logistic Regression Analysis of DD Practice of T2DM Patients}

We undertook univariate analysis between a dependent variable (DD practice of T2DM patients) and independent variables (sociodemographic and disease-related characteristics of T2DM patients and their FMs). Age, occupational status, residence, sources of medical expenses, smoking status, alcohol consumption, receipt of dietary-health education, T2DM duration, number of complications and DM history of T2DM patients, and sex, occupational status, and caregiving duration of FMs had a significant impact on the DD practice of $\mathrm{T} 2 \mathrm{DM}$ patients $(\mathrm{P}<0.05)$. Further logistic regression analysis revealed that the DD knowledge and attitude, occupation, residence, number of complications and family history of T2DM patients, and the sex and DD knowledge of FMs were significantly associated with the DD practice of T2DM patients (Table 5).

\section{Discussion}

We undertook, for the first time, a study on the KAP towards DD among the FMs of Chinese people with T2DM, and its influence on the KAP of such patients. Such a study could provide insights into how FM interventions can reduce the burden of T2DM.

Study findings indicated that the dietary attitude of Chinese T2DM patients was moderate and that dietary knowledge and practice was poor. These data are in accordance with results from studies in China and South Africa. ${ }^{5,8}$ However, JING and colleagues showed that the score for dietary practices among Chinese DM patients was much higher than that for knowledge and attitude. ${ }^{4}$ Studies on KAP towards DMrelated health in Nepal and Pakistan revealed low overall KAP scores among DM patients. ${ }^{13,16}$ Studies in Iran and South Africa showed a good level of KAP on DM selfmanagement and glycemic control, respectively, among people with DM. ${ }^{7,14}$ These mixed findings may be associated

Table 5 Logistic Regression Analysis of the Dietary Practice of T2DM Patients

\begin{tabular}{|c|c|c|c|c|c|c|c|c|}
\hline & Variables & B & SE & $\boldsymbol{\beta}$ & $t$ & $\mathbf{p}$ & $\boldsymbol{F}$ & $R^{2}$ \\
\hline \multirow[t]{10}{*}{ Patients' dietary practice } & & & & & & & 18.379 & 0.393 \\
\hline & (constant) & & & & 9.367 & $<0.001$ & & \\
\hline & Patients' dietary knowledge score & 0.187 & 0.043 & 0.262 & 4.367 & $<0.001$ & & \\
\hline & Patients' dietary attitude score & 0.390 & 0.077 & 0.277 & 5.082 & $<0.001$ & & \\
\hline & Patients'occupation (unemployed) & 2.154 & 0.734 & 0.157 & 2.934 & 0.004 & & \\
\hline & Patients' family history of DM (yes) & -2.021 & 0.739 & -0.145 & -2.736 & 0.007 & & \\
\hline & Patients' residence (rural areas) & -2.941 & 0.881 & -0.175 & -3.338 & 0.001 & & \\
\hline & FM's sex (female) & -2.554 & 0.771 & -0.177 & -3.312 & 0.001 & & \\
\hline & FM's dietary knowledge score & 0.113 & 0.045 & 0.146 & 2.487 & 0.014 & & \\
\hline & Patients'complications $(\mathrm{I}+)$ & 1.480 & $0.720^{\prime}$ & 0.108 & 2.054 & $0.04 I$ & & \\
\hline
\end{tabular}

Abbreviations: B, unstandardized coefficients; SE, standard error of the unstandardized coefficient; $\beta$, standardized coefficient. 
with the difference: (i) medical systems, economic systems, and DM-related education in different developing countries; (ii) number of patients and questionnaire types employed.

The dietary KAP scores of FMs indicated that their dietary attitude was moderate and dietary knowledge and practice were poor (similar to the dietary KAP of T2DM patients). Consistent with T2DM patients, dietary knowledge of their FMs on the ratio and sources of three main macronutrients, and detailed nutrient composition and calculations, were much worse than dietary general knowledge. Moreover, the weakest knowledge was on how to calculate the ideal weight for DM patients (which is the basis of weight management and dietary control). This information should be emphasized and strengthened during DD education. More than $95 \%$ of FMs perceived execution of DD as "quite important" or "very important" and $>90 \%$ of them would like to receive DD education, indicating that they have high awareness of the importance of DD. FMs had confidence in supervising and helping relatives with T2DM with diet management, especially in accepting the inconvenience of dietary differences between patients and other FMs and the necessity of long-term perseverance in supervision and help. FMs had the least confidence in addressing the issue that T2DM patients felt that DD were not suitable for them.

The score for FMs supervising and helping T2DM patients with healthier ways of cooking was low. This might be because traditional Chinese food is often wokfried, braised in soy sauce, and smoked. Moreover, supervising and helping T2DM patients with snack management showed a low score, which may have been because they were living in a household of 2-3 generations. FMs provided the least help in adding coarse food grains to staple food for relatives with T2DM.

We showed that the association between the scores for KAP of T2DM patients were pairwise significantly positive. These data are in line with studies showing an improved attitude and practice score with increasing knowledge scores. ${ }^{6,7,34,35}$ The correlations among scores for KAP of T2DM patients and those of their FMs were pairwise significantly positive, demonstrating interactions between T2DM patients and FMs. ${ }^{9,11,12,17,19}$ The dietary practice of FMs had a weaker positive correlation than dietary knowledge and attitude to the dietary practice of T2DM patients, which might be because FM's behaviors are not always supportive and helpful. ${ }^{10,20-25}$ Studies have demonstrated that FMs providing the most support also had obstructive behaviors, and that supportive and obstructive behaviors were often experienced in the same area of self- care. ${ }^{11,20,24-28}$ The dietary attitude of FMs had a remarkably positive correlation to that of T2DM patients, which may reflect a positive attitude that could help patients build confidence to relieve stress in diet control., ${ }^{9,29-33}$ Likewise, FMs' dietary knowledge had a remarkable positive correlation with that of T2DM patients. Furthermore, 5.3\% of T2DM patients accepted DD knowledge only from their relatives. Though the dietary attitude score of FMs was moderate, the scores for dietary knowledge and practice were low. Hence, FMs know the importance of DD but most of them do not know how to help, a hypothesis that is in accordance with results from the international Diabetes Attitudes Wishes and Needs 2 study. ${ }^{29}$

The occupational status of T2DM patients influenced their dietary practices, which suggested that unemployed T2DM patients could undertake better dietary practice than employed T2DM patients. These data are in line with results from studies by $\mathrm{Li}$ and colleagues ${ }^{6}$ and Asmelash and coworkers, ${ }^{14}$ who found that KAP scores were significantly higher in retired patients than in those currently employed patients. This observation could be related to the fact that employed patients have careers to maintain, so their work and accompanying social activities restrict them from being concerned about their disease. $^{6,14,36,37}$ Male FMs had a stronger influence on the dietary practice of T2DM patients than female FMs. We speculate that this observation could be because males have more authority over females in Chinese households. Hence, females comply with males' suggestions and supervisions, whereas males' traditional characteristics of autonomy, dominance, and stoicism may stop them from accepting supervision from females. ${ }^{36}$

\section{Conclusion}

The dietary attitude of FMs was moderate but dietary knowledge and practice were poor. Dietary KAP was positively correlated with T2DM patients and their FMs.

\section{Data Sharing Statement}

The data used to support the findings of this study are available from the corresponding author Mengyin Cai upon request.

\section{Ethics Approval and Informed Consent}

We confirm that this study was conducted in accordance with the Declaration of Helsinki. The study was approved 
by the ethics committee of the Third Affiliated Hospital of Sun Yat-sen University ([2019]02-565-01). All participants signed informed consent before they participated.

\section{Funding}

This research has been supported by Chinese Nursing Association (ZHKY202023).

\section{Disclosure}

The authors report no conflicts of interest in this work.

\section{References}

1. Saeedi P, Petersohn I, Salpea P, et al. Global and regional diabetes prevalence estimates for 2019 and projections for 2030 and 2045: results from the international diabetes federation diabetes atlas, 9th edition. Diabetes Res Clin Pract. 2019;157:107843. doi:10.1016/j. diabres.2019.107843

2. American Diabetes Association. Standards of Medical Care in diabetes-2020. Diabetes Care. 2020;43(Supplement 1).

3. Evert AB, Dennison M, Gardner CD, et al. Nutrition therapy for adults with diabetes or prediabetes: a consensus report. Diabetes Care. 2019;42(5):731-754. doi:10.2337/dci19-0014

4. Jing LL, Chen W, Sun ZL, et al. Investigation into knowledge, attitude, and practice regarding medical nutrition therapy among patients with diabetes in China: results from a national multicenter cross-sectional study. J Diabetes. 2017;9(9):865-873. doi:10.1111/ 1753-0407.12500

5. Wang H, Song Z, Ba Y, Zhu L, Wen Y. Nutritional and eating education improves knowledge and practice of patients with type 2 diabetes concerning dietary intake and blood glucose control in an outlying city of China. Public Health Nutr. 2014;17(10):2351-2358. doi: $10.1017 /$ S1368980013002735

6. Li Z, Jin H, Chen W, et al. Influencing factors of knowledge, attitude, and practice regarding medical nutrition therapy in patients with diabetes: a national cross-sectional study in urban China. $J$ Diabetes Res. 2017;2017:8948452. doi:10.1155/2017/8948452

7. Karbalaeifar R, Kazempour-Ardebili S, Amiri P, Ghannadi S, Tahmasebinejad Z, Amouzegar A. Evaluating the effect of knowledge, attitude and practice on self-management in patients with type 2 diabetes. Acta Diabetol. 2016;53(6):1015-1023. doi:10.1007/ s00592-016-0905-6

8. Fatema K, Hossain S, Natasha K, et al. Knowledge attitude and practice regarding diabetes mellitus among Nondiabetic and diabetic study participants in Bangladesh. BMC Public Health. 2017;17 (1):364. doi:10.1186/s12889-017-4285-9

9. Torenholt R, Schwennesen N, Willaing I, et al. Systematic review or meta-analysis: lost in translation-the role of family in interventions among adults with diabetes: a systematic review. Diabet Med. 2014;31(1):15-23. doi:10.1111/dme.12290

10. Mayberry LS, Harper KJ, Osborn CY. Family behaviors and type 2 diabetes: what to target and how to address in interventions for adults with low socioeconomic status. Chronic Illn. 2016;12(3):199-215. doi: $10.1177 / 1742395316644303$

11. Mayberry LS, Osborn CY. Family support, medication adherence, and glycemic control among adults with type 2 diabetes. Diabetes Care. 2012;35(6):1239-1245. doi:10.2337/dc11-2103

12. Baig AA, Benitez A, Quinn MT, Burnet DL. Family interventions to improve diabetes outcomes for adults. Ann N Y Acad Sci. 2015;1353 (1):89-112. doi:10.1111/nyas. 12844
13. Gautam A, Bhatta DN, Aryal UR. Diabetes related health knowledge, attitude and practice among diabetic patients in Nepal. BMC Endocr Disord. 2015;15:25. doi:10.1186/s12902-015-0021-6

14. Asmelash D, Abdu N, Tefera S, Baynes HW, Derbew C. Knowledge, attitude, and practice towards glycemic control and its associated factors among diabetes mellitus patients. $J$ Diabetes Res. 2019;2019:2593684. doi:10.1155/2019/2593684

15. Adam L, O'Connor C, Garcia AC. Evaluating the impact of diabetes self-management education methods on knowledge, attitudes and behaviours of adult patients with type 2 diabetes mellitus. Can J Diabetes. 2018;42(5):470-477.e2. doi:10.1016/j.jcjd.2017.11.003

16. Zeb A. Knowledge attitude and practice of diet and exercise among diabetic patients for normal plasma glucose level. Int $J$ Sci Res Public. 2017;1(7).

17. Fisher L, Chesla CA, Skaff MM, et al. The family and disease management in Hispanic and European-American patients with type 2 diabetes. Diabetes Care. 2000;23(3):267-272. doi:10.2337/ diacare.23.3.267

18. Xu Y, Toobert D, Savage C, Pan W, Whitmer K. Factors influencing diabetes self-management in Chinese people with type 2 diabetes. Res Nurs Health. 2008;31(6):613-625. doi:10.1002/nur.20293

19. Hu J, Wallace DC, McCoy TP, Amirehsani KA. A family-based diabetes intervention for Hispanic adults and their family members. Diabetes Educ. 2014;40(1):48-59. doi:10.1177/0145721713512682

20. Mayberry LS, Osborn CY. Family involvement is helpful and harmful to patients' self-care and glycemic control. Patient Educ Couns. 2014;97(3):418-425. doi:10.1016/j.pec.2014.09.011

21. Mayberry LS, Rothman RL, Osborn CY. Family members' obstructive behaviors appear to be more harmful among adults with type 2 diabetes and limited health literacy. J Health Commun. 2014;19 (Suppl 2):132-143. doi:10.1080/10810730.2014.938840

22. Vissenberg C, Nierkens V, van Valkengoed I, et al. The impact of a social network based intervention on self-management behaviours among patients with type 2 diabetes living in socioeconomically deprived neighbourhoods: a mixed methods approach. Scand $J$ Public Health. 2017;45(6):569-583. doi:10.1177/ 1403494817701565

23. McEwen MM, Pasvogel A, Murdaugh C, Hepworth J. Effects of a family-based diabetes intervention on behavioral and biological outcomes for Mexican American adults. Diabetes Educ. 2017;43 (3):272-285. doi:10.1177/0145721717706031

24. Vongmany J, Luckett T, Lam L, Phillips JL. Family behaviours that have an impact on the self-management activities of adults living with type 2 diabetes: a systematic review and meta-synthesis. Diabet Med. 2018;35(2):184-194. doi:10.1111/dme.13547

25. Loskutova NY, Tsai AG, Callen E, et al. Differences in perspectives regarding diabetes management between health care providers and patients. Transl Behav Med. 2018;8(3):328-340. doi:10.1093/tbm/ iby024

26. Rutten GEHM, van Vugt HA, de Weerdt I, de Koning E. Implementation of a structured diabetes consultation model to facilitate a person-centered approach: results from a nationwide dutch study. Diabetes Care. 2018;41(4):688-695. doi:10.2337/dc17-1194

27. Kang CM, Chang SC, Chen PL, et al. Comparison of family partnership intervention care vs. conventional care in adult patients with poorly controlled type 2 diabetes in a community hospital: a randomized controlled trial. Int J Nurs Stud. 2010;47 (11):1363-1373. doi:10.1016/j.ijnurstu.2010.03.009

28. Choi SE. Diet-specific family support and glucose control among Korean immigrants with type 2 diabetes. Diabetes Educ. 2009;35 (6):978-985. doi:10.1177/0145721709349220

29. Kovacs Burns K. Research: educational and psychological issues diabetes attitudes, wishes and needs second study (DAWN2 ${ }^{\mathrm{TM}}$ ): cross-national benchmarking indicators for family members living with people with diabetes. Diabet Med. 2013;30:778-788. doi:10.1111/dme.12239 
30. Trief PM, Fisher L, Sandberg J, et al. Health and psychosocial outcomes of a telephonic couples behavior change intervention in patients with poorly controlled type 2 diabetes: a randomized clinical trial. Diabetes Care. 2016;39(12):2165-2173. doi:10.2337/dc16-0035

31. Weinger K, de Groot M, Cefalu WT. Psychosocial research and care in diabetes: altering lives by understanding attitudes. Diabetes Care. 2016;39(12):2122-2125. doi:10.2337/dc16-2056

32. Berry E, Davies M, Dempster M. Managing type 2 diabetes as a couple: the influence of partners' beliefs on diabetes distress over time. Diabetes Res Clin Pract. 2018;141:244-255. doi:10.1016/j. diabres.2018.05.020

33. Broadbent E, Donkin L, Stroh JC. Illness and treatment perceptions are associated with adherence to medications, diet, and exercise in diabetic patients. Diabetes Care. 2011;34(2):338-340. doi:10.2337/ dc10-1779

34. Vedhara K, Dawe K, Wetherell MA, et al. Illness beliefs predict self-care behaviours in patients with diabetic foot ulcers: a prospective study. Diabetes Res Clin Pract. 2014;106(1):67-72. doi:10.1016/j.diabres.2014.07.018
35. Bains SS, Egede LE. Associations between health literacy, diabetes knowledge, self-care behaviors, and glycemic control in a low income population with type 2 diabetes. Diabetes Technol Ther. 2011;13(3):335-341. doi:10.1089/dia.2010.0160

36. Mathew R, Gucciardi E, De Melo M, Barata P. Self-management experiences among men and women with type 2 diabetes mellitus: a qualitative analysis. BMC Fam Pract. 2012;13:122. doi:10.1186/ 1471-2296-13-122

37. Gupta L, Khandelwal D, Lal PR, Gupta Y, Kalra S, Dutta D. Factors determining the success of therapeutic lifestyle interventions in diabetes - role of partner and family support. Eur Endocrinol. 2019;15 (1):18-24. doi:10.17925/EE.2019.15.1.18

\section{Publish your work in this journal}

Diabetes, Metabolic Syndrome and Obesity: Targets and Therapy is an international, peer-reviewed open-access journal committed to the rapid publication of the latest laboratory and clinical findings in the fields of diabetes, metabolic syndrome and obesity research. Original research, review, case reports, hypothesis formation, expert opinion and commentaries are all considered for publication. The manuscript management system is completely online and includes a very quick and fair peer-review system, which is all easy to use. Visit http://www.dovepress.com/testimonials.php to read real quotes from published authors. 